\title{
OS CARNAVAIS DE NEWTON CAVALCANTI
}

Michel Masson (PUC-Rio)

Tendo como referência a obra em papel de Newton Cavalcanti (1930-2006) recentemente catalogada, o texto analisa as gravuras de temática carnavalesca, que se afirmam, a nosso ver, como ponto nodal na produção do artista.

NEWTON CAVALCANTI, GRAVURA, CARNAVAL.

MASSON, Michel. Os carnavais de Newton Cavalcanti. Textos escolhidos de cultura e arte populares, Rio de Janeiro, v.12, n.2, p. 7-19, nov. 2015. 


\section{THE CARNIVALS OF NEWTON CAVALCANTI}

Michel Masson (PUC-Rio)

Based on the works on paper of Newton Cavalcanti (19302006) recently cataloged, the text analyzes the engravings about carnival, which we view as a nodal point in the artist's production.

NEWTON CAVALCANTI; ENGRAVING; CARNIVAL.

MASSON, Michel. Os carnavais de Newton Cavalcanti. Textos escolhidos de cultura e arte populares, Rio de Janeiro, v.12, n.2, p. 7-19, nov. 2015. 
No início dos anos 1970, por ocasião da exposição Mundo Fantástico realizada no Museu Nacional de Belas Artes, Newton Cavalcanti explicava que seriam exibidas duas fases do seu trabalho: uma com temática popular nordestina e outra de atmosfera psicológica, caráter mais introspectivo; "imagens que refletem a realidade de um mundo secreto". ${ }^{1} \mathrm{~A}$ bem da verdade, esquematicamente, tal divisão pode ser estendida a toda a sua obra, conquanto não se restrinja a ideia do "popular" ao âmbito do Nordeste somente. Nesses termos, haveria o Newton dos mitos brasileiros, cenários e personagens descritas por violeiros e contadeiras de estórias, animais encantados, "políticos ambiciosos e decrépitos, beatos agnósticos, senhores de engenho, cangaceiros e amas de leite ${ }^{2 \prime}$; enfim, o Newton dos temas relacionados à cultura popular, com ênfase no folclore e na tradição afro-brasileira: Festa no Céu, Papagaio de Acelóis, Saci-Pererê, Ganga Zumba, Negrinho do Pastoreio, São Jorge, Yara, Chico Rei. Por outro lado, haveria o Newton de delirante mitologia própria, constituída de uma iconografia de grotescas personagens inventadas: estranhos seres humanos segurando tigelas de comida - que lembram oferendas religiosas do candomblé -, andrógenos de duas cabeças (Figura 1), criaturas híbridas kafkianas tocando instrumentos, lobos, insetos gigantes, entre outros tipos extraordinários. ${ }^{3}$ Entretanto, esse modelo de abordagem se mostra verdadeiramente válido se tomado menos como uma polarização rígida do que como um esquema que admite nuanças e entrecruzamentos. De saída, comum às duas vertentes é a evidente atração pela fantasia. Não por acaso, o conjunto de trabalhos sobre o carnaval ${ }^{4}$ se mostra como o momento por excelência em que éthos popular e imaginário pessoal tornam-se indissociáveis; algo, não obstante, repleto de ressonâncias ambíguas. Para melhor compreender isso, há que analisar um traço fundamental em Newton, a saber, o seu expressionismo.

\section{DUAS FACES, UM EU}

Nascido em Bom Conselho de Papa-Caça, agreste pernambucano, Newton passou a adolescência em Salvador, até mudar-se para o Rio de Janeiro em 1951. ${ }^{5}$ $\mathrm{Na}$ "cidade perturbadora e bela como um corpo de mulher" (CAVALCANTI, 1985), passou a frequentar aulas de modelagem no Liceu de Artes e Ofícios. Sob orientação de Adir Botelho, ingressou na Escola Nacional de Belas Artes em 1954, tornando-se aluno nas oficinas de gravura de Raimundo Cela. Logo, conheceu Oswaldo Goeldi, com quem travou amizade. Nesse momento, pode-se dizer, a "fantasia do interior do nordeste que estava em sua raiz" ${ }^{6}$ encontrou a tradição expressionista, a qual, levada a cabo pelo mestre, foi exercida pelo jovem Newton menos por escolha do que vocação e temperamento. ${ }^{7}$ Naturalmente, o ponto de conta- 


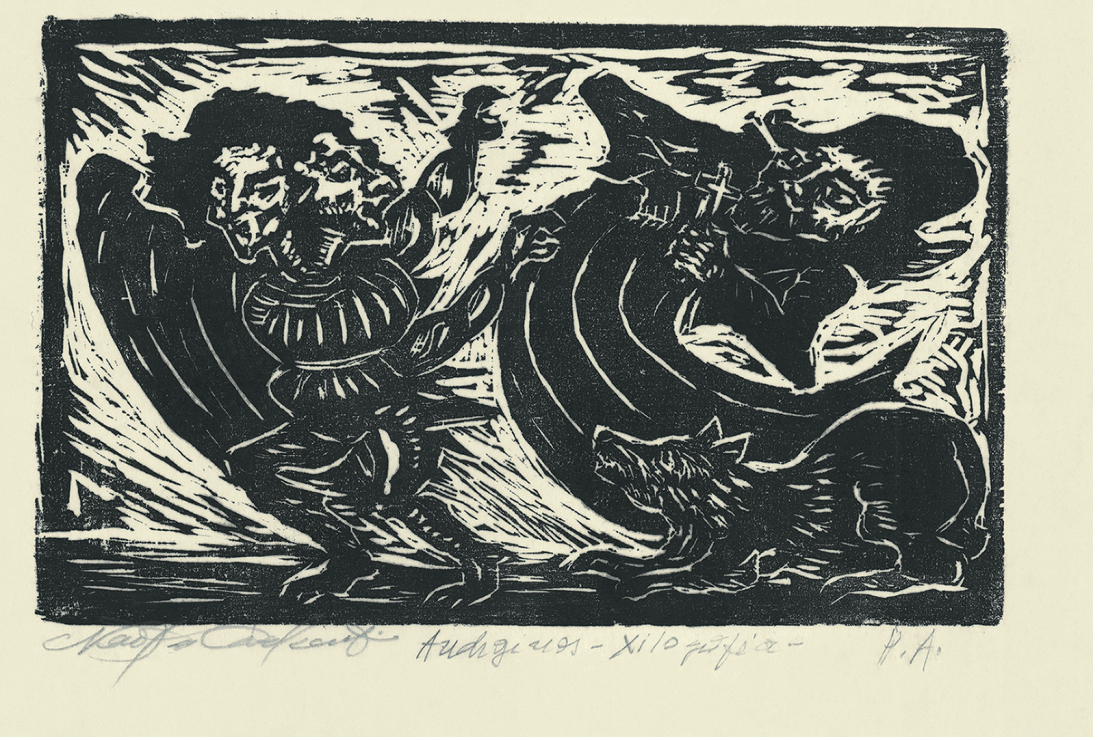

Figura 1: Andrógenos, s.d., xilogravura, P.A., 32 x $43 \mathrm{~cm}$

to foi a xilogravura, técnica artesanal arcaica com origens remotas, ${ }^{8}$ recuperada pelo expressionismo com raízes no norte da Europa, utilizada no Brasil, em regra, nos livretos de cordel.

Predominam na fase inicial de Newton motivos retirados da realidade nordestina e seus tipos: seresteiros, soldados e policiais, pitorescas cenas de camponeses tocando burricadas e lavadeiras carregando trouxas na cabeça. Não obstante, salta aos olhos em alguns desses primeiros trabalhos a mistura entre real e irreal. O jagunço luta com demônios, o homem-lobo dança ao som do violeiro, a mulher cujo rosto é uma caveira deita-se nos braços do cangaceiro.

Para alguém como Newton, um expressionista versado no universo nordestino, aderir ao imaginário público da cultura popular ou mergulhar nas profundezas de seu mundo psicológico privado corresponde, sem contradição alguma, ao gesto decidido de aproximação de si mesmo (MASSON, 2012, p. 20). Assimilada através da vivência, jamais assumida a partir de pontos de vista extrínsecos, a cultura popular eventualmente torna-se instância para autoexpressão e realização do artista. Gravuras como Tentação de Santo Antônio, O Alcóolatra e A Chegada de Lampião no Inferno - em que a figura humana é atacada por criaturas animalescas no céu ou nas profundezas da terra - não deixam de ser verdadeiras alegorias de um eu lírico que, inevitavelmente, não encontra medida no 


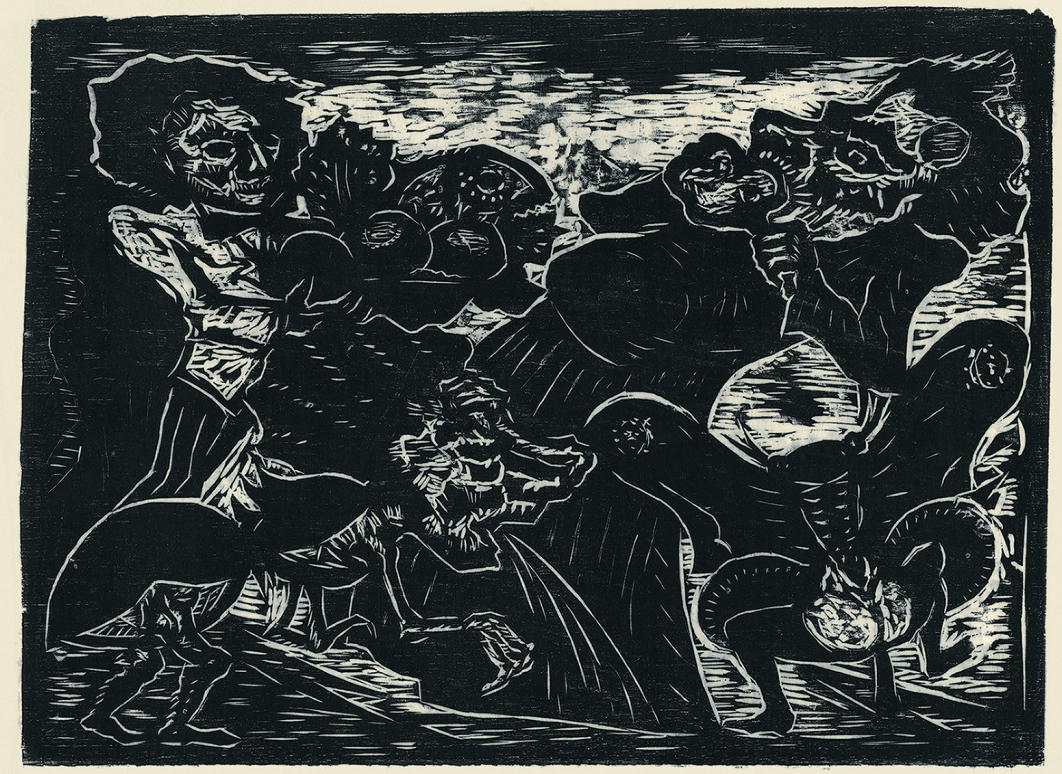

Figura 2: Sem título, s. d., xilogravura, $39 \times 47 \mathrm{~cm}$

mundo: embates supraterrenos remetem aos íntimos impasses, dilemas e tormentos de Newton. (Figura 2)

Sem mais mediações, transparece nas figurações de panorama psíquico do artista seu pathos emocional. Personagens bizarras ${ }^{9}$ tomam parte em movimentadas aglomerações de atmosfera a um só tempo animadas e macabras, surpreendentes e perturbadoras, afetadas e escatológicas. ${ }^{10}$ Trata-se de inquietantes fabulações estranhamente subtraídas de narrativa, no limite da figuração: cenas desambientadas, agregados ilógicos de impressionantes seres com forte apelo simbólico; "recortes mudos mas de visualidade estridente" (MASSON, 2012, p. 14) os quais ensejam uma dimensão psicológica real e palpável. Entranhar-se, estranhar-se e agir. Em pauta, a ânsia expressionista de comunicação, o ambíguo impacto de atraentes repulsas. "A coisa que mais participa e comunica", certa vez afirmou Newton, "é o conflito". 11

\section{BAILES NO LIMBO, FANTASMAGORIA DO EGO}

O período carnavalesco é um estuário para onde correm e onde se encontram rios raciais. De Jubiabá a João da Bahiana e Joãozinho da Comeia, veneráveis pais de santo mineiros, baianos e cariocas 


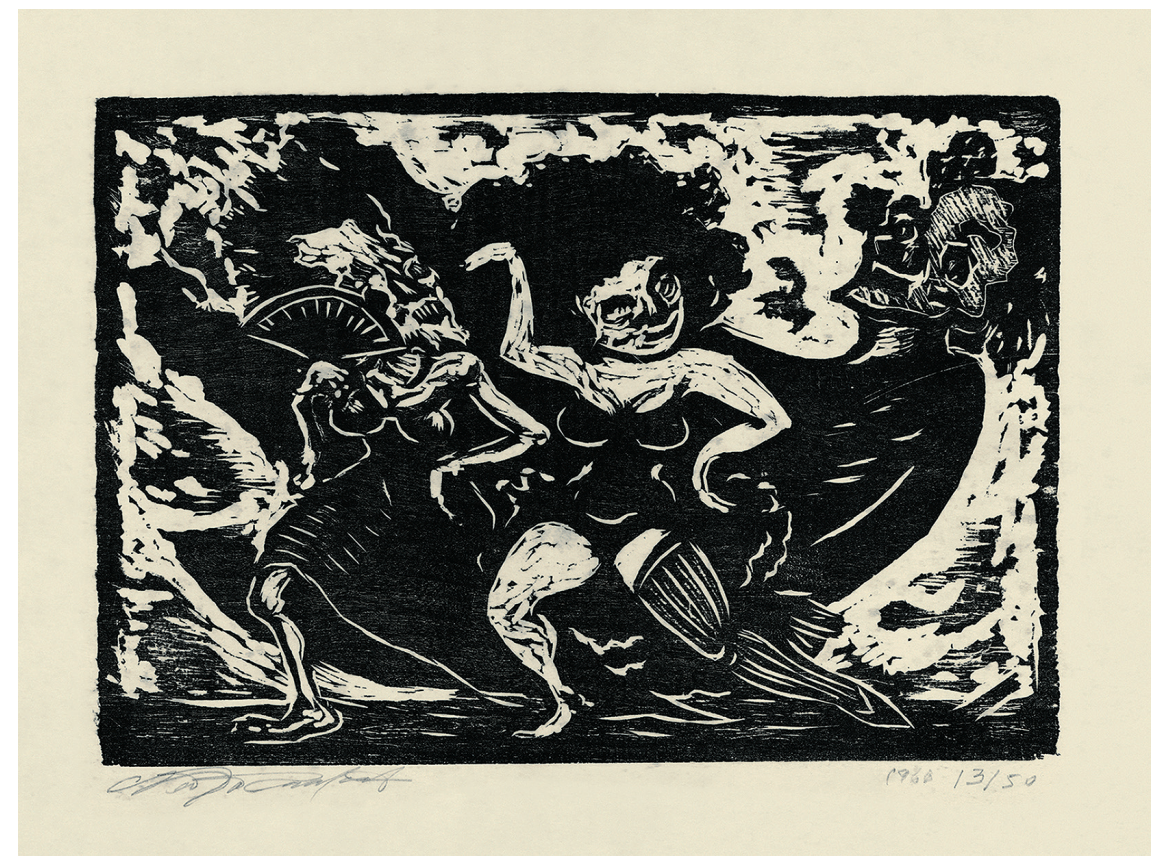

Figura 3: Sem título (Carnaval), 1966, xilogravura, 13/50, 36,5 x 47,5cm

fugindo das perseguições policiais e religiosas devolveram às elites colonizadoras positivistas, republicanas ou da monarquia imperial surpreendendo-as através da força de uma expressão artística e cultural incontrolável pela vigilância destes poderes e que jamais nasceu de uma imposição de cima para baixo (CAVALCANTI, 1992).

Em nenhum outro conjunto de trabalhos de Newton as instâncias popular e psíquica encontram-se tão presentes e indistintas quanto nas cenas de carnaval, iniciadas, ao que tudo indica, por volta de meados da década de $1960 .{ }^{12} \mathrm{Ne}-$ las, a típica festa brasileira vem transfigurada segundo o modo de ser do artista, sujeito existencial para quem eu e mundo se constituem sob a forma problemática da obra. Fazendo do carnaval sua imagem e semelhança, Newton encarna e também é encarnado, diluindo de maneira drástica, sob o alto contraste do preto e branco, os limites bem definidos do que antes era distinto e antagônico: coletivo e individual, exterior e interior, público e privado. ${ }^{13} \mathrm{O}$ carnaval transmudase em persona.

Prepondera em tais troças a figura feminina, mulheres com apelo sensual - ora de corpo à mostra, ora em lindos vestidos -, portando leques e usando meias, ladeadas por misteriosos foliões: tipos que avultam envoltos em capas, 


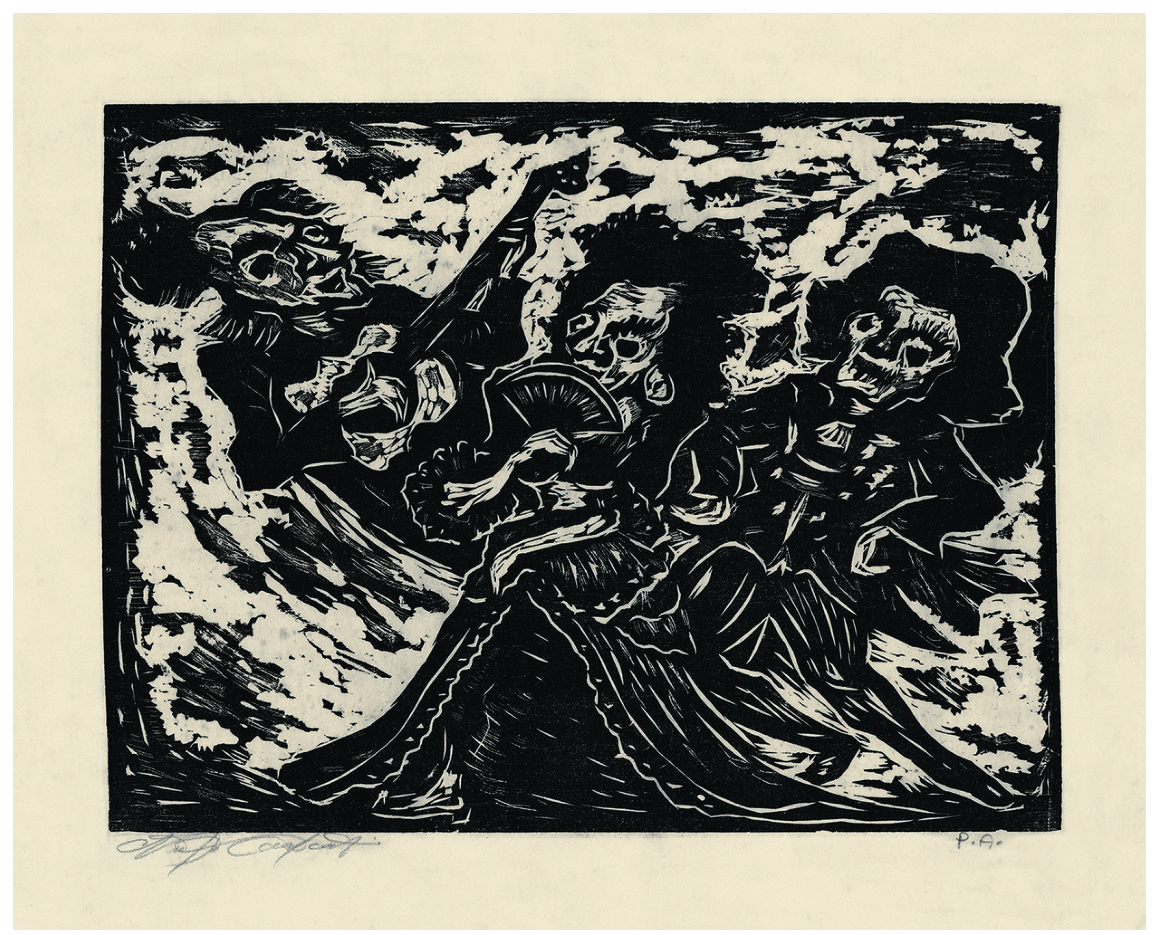

Figura 4: Sem título (Carnaval), s. d., xilogravura, P.A., $40,5 \times 48 \mathrm{~cm}$

seres alados tocando cornetas, ${ }^{14}$ indivíduos de muletas empunhando copos, ${ }^{15}$ os quais nos envolvem numa atmosfera em muito semelhante àquela já descrita. Aqui, fantasias beiram disfarces (figuras 3 e 4).

Consubstanciadas por um estar no mundo que responde às condições efetivas da existência, as personagens divertem-se unidas pelo elã vital que move Newton. Trata-se, novamente, de pequenas concentrações, agora, entretanto, deliberadamente promíscuas. Emaranhados dinâmicos prenhes de intensa energia, os quais trazem à tona uma esfera psíquica impregnada de ambivalências: libertinagem e libido, afetação e delicadeza, aspereza e doçura. Maravilhosas pândegas em que mulheres ora graciosamente requebram os quadris com as mãos na cintura, ora excretam enquanto, indiferente, o malicioso anão segura sua perna e a morde com volúpia. Tais invariáveis belos caos, de prazeres depravados, fatalmente nos remetem à série Los Caprichos, de Francisco de Goya.

Longe de ser a encenação de um teatro mental, simples projeção do interno sobre o externo, pode-se dizer, o carnaval é o verdadeiro mundo de Newton. Ou melhor, seu único e possível mundo, vivido em ato, sem enredos prévios. Momento por excelência do não cerceamento ou jugo moral, a festa profana é o lu- 
gar do exercício pleno de sua liberdade de ação e imaginação, propício a extravasar as pulsões reprimidas de seu incontrolável ímpeto, dar vazão, enfim, às ambivalências do eu. "O amor me eleva à essência divina", afirma o artista, "e me traio com ódio e a vingança humanas" (CAVALCANTI, 1985). A vida para Newton sempre foi um difícil duelo, mas também uma celebração.

Os carnavais de Newton guardam algo de enigmático. Quanto mais persiste nosso olhar atento, menos certezas temos, e o que à primeira vista eram figuras mascaradas, aos poucos se revelam corpos acaveirados. Incertos, oscilamos. Não há como saber se estamos diante de pessoas fantasiadas ou entes do além, evento banal ou baile extraordinário. Ao contrário das famosas calaveras do artista mexicano José Guadalupe Posadas (1852-1913), ${ }^{16}$ não se trata aqui simplesmente de esqueletos vivos. Tanto assustadoras quanto amistosas, empáticas, ossaturas cheias de carnalidade evoluem e nos suscitam a dúvida, suspendem pontos de vista absolutos. Nada é o que aparenta ser. Justamente, advém de tal aspecto insituável a potência estética desses folguedos. Em tais circunstâncias, em que os opostos convivem, não há por que escolher entre mundano ou sobrenatural, alegre ou sombrio, sensual ou mórbido, verdade ou ilusão, real ou sobrenatural, luz ou trevas, sagrado ou profano, bem ou mal, céu ou inferno, e por aí em diante. Afinal, o mundo - que é sempre o nosso mundo - não comporta isto ou aquilo, de maneira excludente. Newton sabe. Ele é farra, também é amargura.

Se "nosso carnaval adquiriu", nas palavras de Newton, "um elo de espiritualidade e até mesmo de religião" (CAVALCANTI, 1992), seus corsos assumem caráter de rituais quase místicos, cortejos que atraem tudo e todos, aproximam díspares. Em última instância, reúnem arte, vida, e também morte, presença velada que sempre paira iminente no sertão brasileiro não menos que no espírito do artista. Newton insiste em flertar com ela, parecendo vê-la como a perfeita parceira de uma divertida dança. Seus carnavais causam espanto e assombro; encantam, evocam.

Mitos e ritos dionisíacos, mediterrâneos, oriundos da Negra África, dos nativos e brancos ibéricos se congregam na glória das raças, sem distinção de credos, tal a comunhão de todas as crenças com o propósito de participação, na comunicação coreográfica dos passistas, sambistas bateristas (CAVALCANTI, 1992).

$\mathrm{Na}$ época em que realizou as gravuras sobre o carnaval, Newton gravou uma série inspirada em A morte escarlate, conto de Edgar Alan Poe narrando a estória do príncipe Próspero que, diante da doença que dizimava a população nos domínios do seu reino, confinou-se com a corte dentro de seu castelo (Figura 5). Aproximadamente no sexto mês, enquanto a peste grassava do lado de fora, brin- 


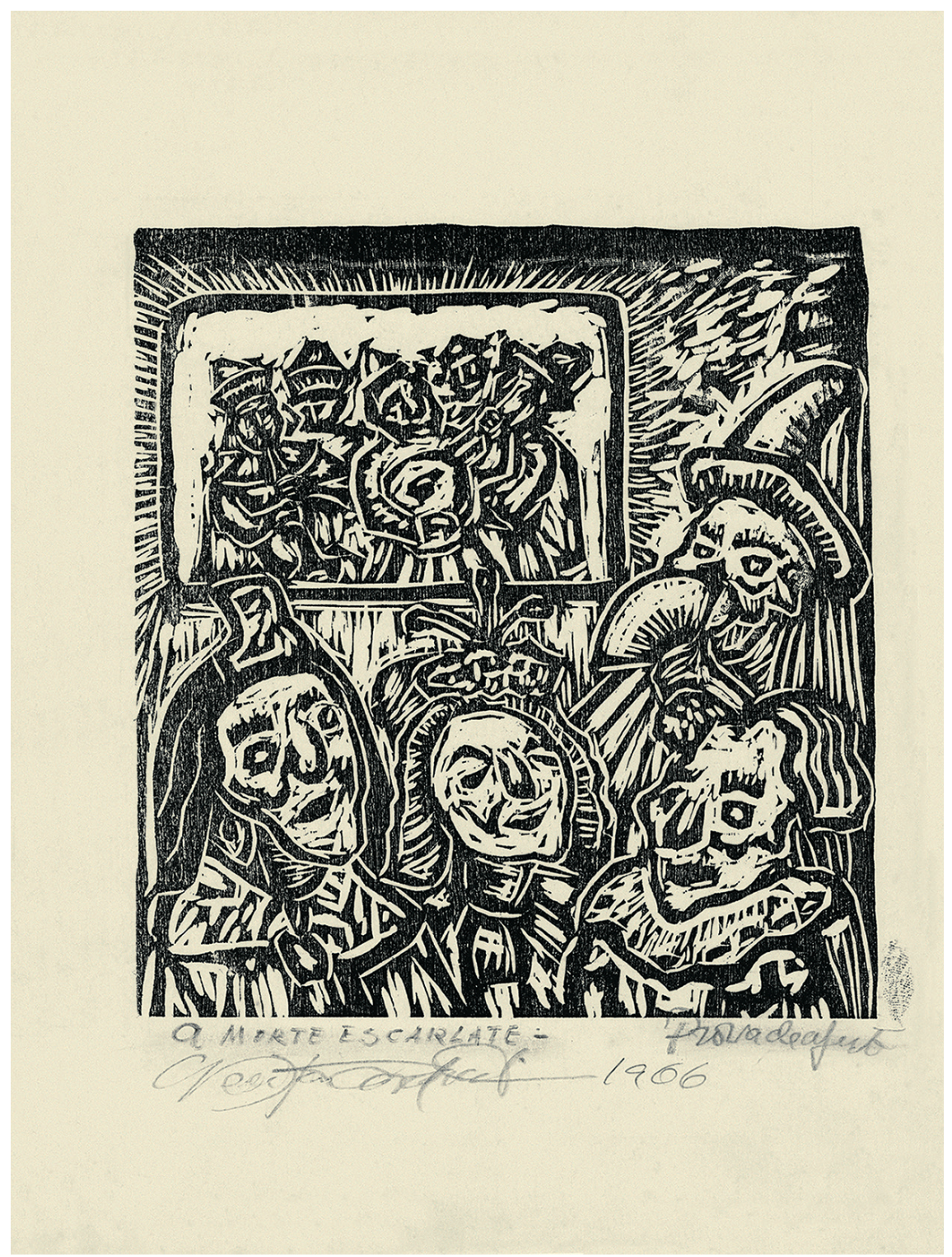

Figura 5: A Morte Escarlate, 1966, xilogravura, P.A., 27,5 x $20 \mathrm{~cm}$

dou os mil amigos promovendo um magnífico baile de máscaras. Tudo transcorria bem até que se percebe a presença de uma figura mascarada: sorrateira, a Morte Vermelha infiltrara-se, e, logo, um a um, todos fenecem. Daí o senso de mistério, os ares refinados - quase corteses - que respiram as folias plebeias de Newton. 


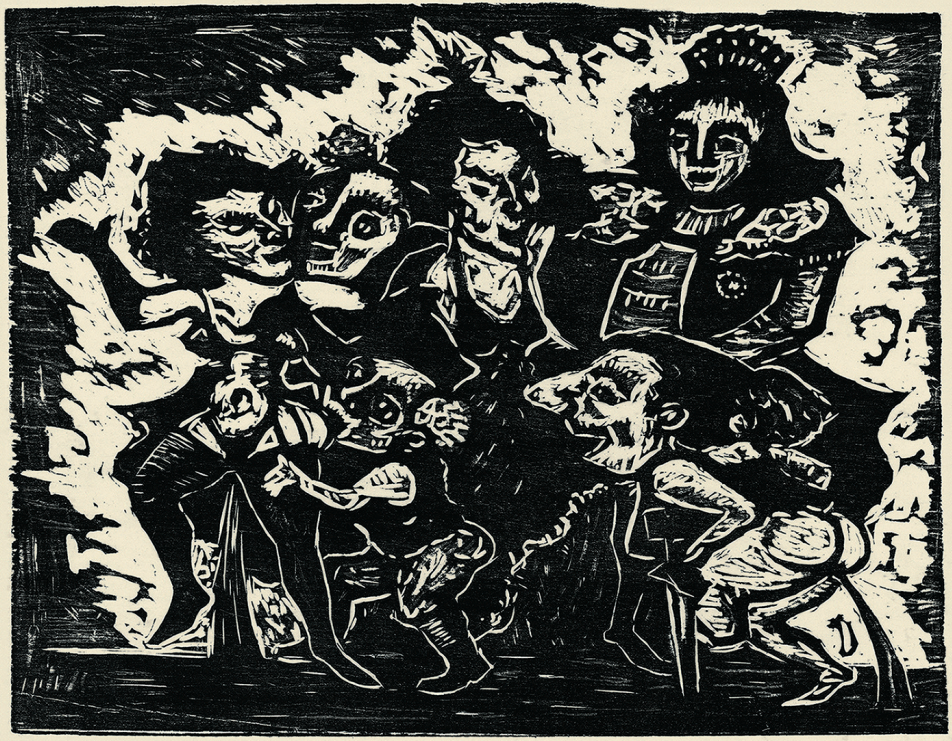

Figura 6: Sem título (Carnaval), s. d., xilogravura, 35,5 x $49 \mathrm{~cm}$

Compreendê-las demanda aceitar seus fantasmas. Poe, Goeldi, Posadas, Goya estão todos presentes na grande festa. ${ }^{17}$

\section{FESTINS BARROCOS, CONTRASSENSOS DA CENA}

A gravura de cordel é meio estática. A minha é mais barroca, mais efervescente (CAVALCANTI, O GLOBO, 15/71979)

Por meio de sua modernidade expressionista, Newton assimilou e reprocessou o que lhe marcou o espírito. Obrigado a assistir a missas quando jovem, cedo tornou-se íntimo da tradição barroca luso-brasileira, ao tomar contato com os altares da Bahia ou ainda com as "fachadas de azulejos decorados como vestidos de noiva brancos bordados de azul" e as "janelas com sacadas (que) testemunhavam muitas histórias, memorizando a marca do tempo de gloriosas traficâncias" (CAVALCANTI, 1985).

Talvez por isso existam, nos seus carnavais, os sentimentos de excesso e exceção, o dinamismo e a exuberância, os delicados movimentos que beiram o teatral, enfim, o horror vacui que impele o entalhe quase incessante de aberturas de luz em meio às grandes áreas entintadas. É impossível, aliás, passarem despercebidas essas estranhas massas luminescentes em contraluz, que envolvem os corpos e como eles se agitam. Espécie de névoa irradiante que, de tanto bri- 
Iho, cega, esses obscuros clarões metafísicos mais escondem do que revelam; fazem das personagens figuras sem fundo, quase sem firmamento.

As cenas de Newton são deliberadamente problematizadas, não composicionais. Espacialidades em circunvolução ao modo do carnaval (Figura 6). Com efeito, a literatura de cordel, canhestra, sem perspectiva, parece misturar-se à verve expressionista de tomar liberdades com o cubo cênico. Desproporcionais, exageradamente aproximadas, as figuras causam impacto imediato; têm presença ostensiva, lembram a pronta comunicabilidade do cordel, a agilidade e rapidez do repente.

Newton toma o carnaval como ele é. Talha menos espaços do que momentos: eventos-aparições em que padece a perspectiva, pequenos instantes de "extremosidade e suspensão", parafraseando os termos definidores do barroco segundo José Antônio Maravall (1997). Imagens-lampejo como os fortuitos encontros em meio ao anonimato da multidão do qual guardamos apenas afetivas lembranças sem rosto.

\section{NOTAS}

1 Matéria publicada no jornal O Globo, Rio de Janeiro, de 15/7/1979 intitulada "No MNBA, 20 anos de Newton Cavalcanti".

2 Matéria do Jornal de Brasília, Brasília, de 18/5/1979 intitulada "Galeria Parnaso mostra os mitos brasileiros".

3 Mesmo séries como Navio Negreiro e Mensagem - resultantes da interpretação de Newton da literatura erudita de Castro Alves e Fernando Pessoa, respectivamente -, Futebol, Édipo, as cenas que retratam eventos e fatalidades do cotidiano - divertidas mesas de bar, brigas de casais, assassinatos, etc. - podem ser tomadas segundo esse prisma, ora por se relacionar à história e cultura brasileiras, ora por denotar muito da personalidade de Newton, fortemente marcada por senso trágico.

4 Ao que tudo indica, o conjunto de gravuras ao qual nos referimos foi produzido entre meados da década de 1960 e início dos anos 70.

5 Em função de perseguições políticas, os pais de Newton se transferiram de Bom Conselho, levando-o - quando tinha em torno de um ano de idade - e seus irmãos para Palmeira dos Índios (AL), e, logo em seguida, para Salvador. Na veIha cidade baiana, Newton cresceria trabalhando como ajudante de pedreiro, perderia um irmão e ganharia outros dois. Vem para o Rio de Janeiro já funcionário público, transferido pela Companhia Vale do Rio Doce.

6 Matéria publicada no jornal O Globo, Rio de Janeiro, de 15/7/1979 intitulada "No MNBA, 20 anos de Newton Cavalcanti". 
7 A respeito do impacto de Goeldi sobre seu trabalho, Newton certa vez declarou: "Eu de fato não sinto que haja uma influência e um tratamento na forma de Goeldi. Alguns críticos souberam que eu era amigo de Goeldi, então inventaram esta história da influência da sua arte sobre a minha." Noutra passagem, afirma: "Ficávamos de $10 \mathrm{~h}$ à meia-noite conversando sem cansaço." "Não tive influência dele, isso é balela. Ele é menos barroco do que eu, mais contido do que eu, sua obra era misteriosa.... Minha influência vem de Goya e do cordel" (Declaração colhida em texto avulso, sem data, publicado pela Prefeitura de Niterói/Fundação de Arte de Niterói intitulado "Ritmos do Mar". Newton Cavalcanti expõe no CCPCM série inspirada em poemas épicos de Fernando Pessoa e Castro Alves.

8 Segundo Martins Filho (1981, p. 9), a xilogravura - a mais rudimentar das formas de gravura, que tem a madeira como matriz - surge na Europa na Idade Média em finais do século XIV.

9 Motivos bastante comuns, por exemplo, são as figuras voando lateralmente no céu ou surgindo por trás do primeiro plano.

10 Desenhos a nanquim datam de 1963.

11 Declaração recolhida em texto intitulado "Newton Cavalcanti: a forma de origem temática", publicado em artigo de jornal não identificado.

12 Das poucas gravuras datadas, grande parte é de 1966.

13 Newton tinha plena consciência desse processo. "Retomei a antiga temática da fantasia popular. Na minha obra, o mito tem a raiz na terra mesmo. São os mitos comuns de todos nós, sul-americanos. (...) A maneira de transpor o mito para a criação, a obra de arte, é que depende do mundo individual, da cultura própria do artista. Esta mobilização criadora é, evidentemente, inconsciente, pelo menos para mim". Declaração colhida em matéria de jornal não identificado intitulada "Cavalcanti, o velho e o novo".

14 Nos dizeres do artista, "personagens alados e criaturas voadoras (que) representam a vida superior livre do casulo, da lagarta" (CAVALCANTI, 1985).

15 Esses corpos mutilados claramente aludem à condição física do artista. Aos 17 anos, Newton perdeu a mão esquerda numa discussão no "elétrico".

16 Com frequência, Newton costuma lançar mão das personagens - sertanejos, vaqueiros ou São Jorge - tratadas ao modo de Posadas.

17 Nesse sentido, o artista não foi tão solitário quanto parece. Embora tenha trabalhado no sentido oposto das correntes abstratas instauradas a partir do início dos anos 50, tanto o informalismo quanto as tendências construtivas, Newton sempre esteve "acompanhado". 


\section{REFERÊNCIAS BIBLIOGRÁFICAS}

CAVALCANTI, Newton. Santos e fiéis da passarela. Jornal do Brasil, Caderno Ideias. Rio de Janeiro, 1/3/1992.

. Trajetórias (volante de exposição). Rio de Janeiro: Museu Nacional de Belas Artes, 1985.

MASSON, Michel (Org.). Newton Cavalcanti: lendas rústicas. Rio de Janeiro: Data Coop, 2012.

MARAVALL, José Antônio. A cultura do barroco: análise de uma estrutura. São Paulo: Edusp, 1997.

MARTINS FILHO, Carlos Botelho. Introdução ao conhecimento da gravura em metal. Rio de Janeiro: Solar Grandjean de Montigny/PUC, 1981.

Michel Masson é doutor em história pela PUC-Rio e curador do Projeto Newton Cavalcanti.

Recebido em: 02/04/2015

Aceito em: 01/06/2015 
